\title{
Effects of endometriosis on sleep quality of women: does life style factor make a difference?
}

\author{
Samaneh Youseflu', Shahideh Jahanian Sadatmahalleh ${ }^{1 *}$ (D), Ghazall Roshanzadeh ${ }^{1}$, Azadeh Mottaghi², \\ Anoshirvan Kazemnejad ${ }^{3}$ and Ashraf Moini ${ }^{4,5,6}$
}

\begin{abstract}
Background: This study aimed to compare the lifestyle factors and SQ between women with and without endometriosis. Also in this essay, the influence of food intake, socio-demographic and clinical characteristics on sleep quality of women with endometriosis was determined.

Methods: Of the 156 infertile women approached for the study, 78 women had endometriosis and 78 were included in the control group. At first, each participant completed a checklist including questions about demographics, physical activity, reproductive and menstrual status. SQ was assessed by the Pittsburgh Sleep Quality Index (PSQI). Dietary data were collected using a validated 147-item semi-quantitative FFQ.

Results: Irregular menstrual status, menorrhagia, dysmenorrhea, pelvic pain, history of abortion, family history of endometriosis were associated with endometriosis risk $(P<0.05)$. In women with physical activity more than $3 \mathrm{~h}$ per week, high consumption of the dairy product, and fruit endometriosis is less common $(P<0.05)$. The total PSQI score, and the scores for subjective sleep quality, sleep latency, sleep disturbance domains were significantly different between the two groups $(P<0.05)$. In women with endometriosis, poor SQ was associated with dysmenorrhea, pelvic pain, dyspareunia, physical activity, and low consumption of the dairy product, fruit, and nut $(p<0.05)$.

Conclusion: In endometriosis women, SQ was lower than healthy individuals. Lifestyle factors can effect on SQ of these patients.
\end{abstract}

Keywords: Endometriosis, Sleep quality, Lifestyle, Diet, Physical activity

\section{Background}

Endometriosis is the benign proliferation of functioning endometrial glands and stroma in ectopic locations outside the uterine cavity [1], which affects an estimated range from 0.7 to $8.6 \%$ in the general population [2]. A high prevalence of dysmenorrhea, dyspareunia, noncyclic pelvic pain, infertility and menstrual disorders

\footnotetext{
* Correspondence: shahideh.jahanian@modares.ac.ir

${ }^{1}$ Department of Midwifery and Reproductive Health, Faculty of Medical Sciences, Tarbiat Modares University, Tehran, Iran

Full list of author information is available at the end of the article
}

(such as menorrhagia, metroragia, spotting) has been seen in these patients $[1,3]$. Although the exact pathophysiology of this disease is not clear, it is believed agents that impress the volume of retrograde menstruation or affect woman's aptitude for implantation of the endometriotic lesion are involved in the appearance and progression of endometriosis [4]. Some of the studies introduced that the appearance of endometriosis has been developed by hormonal and immunological mechanisms, genetic and inflammatory processes, as well as environmental and lifestyle factors [5].

(c) The Author(s). 2020 Open Access This article is licensed under a Creative Commons Attribution 4.0 International License, which permits use, sharing, adaptation, distribution and reproduction in any medium or format, as long as you give appropriate credit to the original author(s) and the source, provide a link to the Creative Commons licence, and indicate if changes were made. The images or other third party material in this article are included in the article's Creative Commons licence, unless indicated otherwise in a credit line to the material. If material is not included in the article's Creative Commons licence and your intended use is not permitted by statutory regulation or exceeds the permitted use, you will need to obtain permission directly from the copyright holder. To view a copy of this licence, visit http://creativecommons.org/licenses/by/4.0/ The Creative Commons Public Domain Dedication waiver (http://creativecommons.org/publicdomain/zero/1.0/) applies to the data made available in this article, unless otherwise stated in a credit line to the data. 
Lifestyle factors play an important role in preventing many chronic diseases. Available evidence on the effect of lifestyle-related factors such as physical activity, nutritional status, body mass index, smoking, and SQ on endometriosis is controversial [1, 6-9]. Therefore, modified lifestyle recommendations in these patients have been discussed. For example, some studies depicted the anti-estrogenic activity of cigarette has a protective effect on endometriosis, others suggested that cigarette with an impact on pro-inflammatory gene overexpression can trigger inflammation $[6,7]$.

Sleep is an essential physiological process that can be impressed by many medical and sleep disorders. Several studies have demonstrated that sleep disorder is a common symptom in women with endometriosis [10, 11]. Recently, a relationship between endometriosis-related symptoms such as pain and sleep disorder has been reported [12]. Arion et al. study reveal that sleep quality of women with endometriosis is associated with poorer quality of life, more depressive symptoms, and bladder pain syndrome [13].

Sleep disorder and changes in the melatonin level can be a diverse effect on the reproductive system [14, 15]. There is compelling evidence to implicate that endogenous melatonin acts as an important analgesic, sleep inducer and regulator of the circadian rhythm, antioxidant, anticarcinogenic, immunoregulator, and anti-inflammatory agent $[14,15]$.

The purpose of the current study was to compare the lifestyle factors (including physical activity levels, diet, BMI, cigarette smoking), and SQ between women with and without endometriosis. Also in this essay, the influence of food intake, socio-demographic and clinical characteristics on sleep quality of women with endometriosis was determined.

\section{Methods}

The study was conducted as a case-control study survey between May 2016 and February 2017 on 156 infertile women (78 women with endometriosis and 78 controls) that attended in Infertility Clinic of Arash Hospital in Tehran, Iran.

During the period of the study, all infertile women who undergone diagnostic laparoscopy were allocated. Based on the laparoscopy results, those women with abnormalities other than endometriosis (eg. endometrial hyperplasia, leiomyoma, and other gynecological cancer) were excluded from the study. Participants were divided into two groups: a case group consisted of 78 women with endometriosis for whom the disease was confirmed by laparoscopy and histology examinations, and a control group consisting of 78 infertile women with a normal pelvis. A control group was selected at the same time as the case group. Controls were selected randomly matched on age, education, and duration of infertility.

Eligibility criteria for inclusion in the study were including age between 18 and 45 years, absence of the history of chronic diseases or mental disorder according to self-report of women, Iranian race, Non-occurrence of bad events in the 12 months ago (e.g. death or illness of family members or close friends, financial difficulties, and etc.)

Ethical approval for the study was obtained from the Regional Ethics Committee at Tarbiat Modares University of Medical Sciences (IR.TMU.REC.1395.358). All women voluntarily participated and signed informed consent.

During the first visit, the weight and height of all women recoursing to the infertility clinic are measured. Body Mass Index (BMI) is calculated as weight divided by height squared $(\mathrm{kg} / \mathrm{m} 2)$.

A socio-demographic checklist including questions about socio-economic status (such as age, educational level, occupational status, income, and smoking history) was completed. The following, questions were asked about menstrual and reproductive characteristics (such as menstrual pattern, cycle regularity, menstrual duration, amount of menstrual bleeding, length of the menstrual cycle, premenstrual spotting, menarche age, presence of dysmenorrhea, dyspareunia and chronic pelvic pain, gravidity, parity, history of using contraception).

Participants were asked to report their exercise times/ week. Based on their response, the participants' physical activity was determined at three levels: low (less than $1 \mathrm{~h}$ per week), moderate (2-3h per week), and high physical activity (more than $3 \mathrm{~h}$ per week).

A semi-quantitative 147-item FFQ was applied to obtain dietary information. This questionnaire included a list of dietary items (with standard serving measures) commonly consumed by Iranians. The Persian version of FFQ has previously been evaluated for both reliability and validity [16]. The participants were asked to report their usual food intake during the previous year on a daily, weekly, monthly and yearly basis; all these were converted to daily intakes. Portion sizes of the consumed food were transformed to grams by using domestic measurement.

All consumed food items were analyzed for their energy and nutrient components by a nutrient database (Nutritionist 4, Mosby Nutritract software, and ver.7.0, N-Squared Computing, Salem, OR, USA).

For assessment of dietary sources of melatonin, we considered food rich of tryptophan including dairy product, nut (peanut, almond, pistachio, and walnuts), fruit (banana, apple, kiwi, peach, and strawberry, orange) and meat (red meat, pultatory, and fish). 
Multiple aspects of SQ during the previous month were assessed using the valid and reliable Persian version of the Pittsburgh Sleep Quality Index (PSQI) [17]. This questionnaire contains 19 items in seven categories (sleep quality, sleep latency, sleep duration, habitual sleep efficiency, sleep disturbances, use of sleeping medication, and daytime dysfunction) on a scale from 0 to 3; so the total score of PSQI is from 0 to 21. A total score higher than 5 identifies poor SQ and scores lower than 5 show the absence of sleep disorder.

Statistical analysis was performed using Statistical Package for Social Science (version 16). To check the variables' normality, Kolmogorov-Smirnoff's (KS) test was run. Comparisons between two groups were done using Independent Samples T-Test, Mann-Whitney's test (MW), Chi-square tests, and logistic regression model.

\section{Results}

Considering general risk factors, menstrual status (OR: 2.80; \%95CI: $1.23-4.38 ; P=0.01$ ), menorrhagia (OR: 2.98; \%95CI: $1.31-3.76 ; P=0.007$ ), dysmenorrhea (OR: 4.61; \%95CI: 3.31-5.18; $P<0.001$ ), pelvic pain (OR: 15.31; \%95CI: $12.95-17.43 ; P<0.001)$, history of abortion (OR: 2.36; \%95CI: 1.05-3.28; $P=0.04$ ), Family history of endometriosis (OR: 4.05; \%95CI: 2.08-7.14; $P=0.04$ ), and high level of physical activity (OR: 0.3; \%95CI: 0.13$0.65 ; P=0.04$ ), were associated with endometriosis risk. There was no significant relationship between, age, age at menarche, level of education, OCP use, BMI, smoking and endometriosis risk $(P>0.05)$ (Table 1$)$.

Table 2 indicates that the intake of dairy products and fruit rich in tryptophan in women with endometriosis is less than the control group $(P=0.02)$. Consumption of other food groups such as vegetables, meat, nut, fast food, and processed snacks was no significant difference between two groups $(P>0.05)$. The total PSQI score $(P<0.001)$ and the scores for the subjective sleep quality $(P=0.002)$, sleep latency $(P<0.001)$, sleep disturbance $(P<0.001)$ domains were significantly different between women with and without endometriosis.

Table 3 shows poor SQ was statistically significantly associated with dysmenorrhea $(p=0.03)$, pelvic pain $(p=0.02)$, dyspareunia $(p=0.04)$, physical activity $(p<$ $0.001)$, and consumption of dairy product $(p=0.03)$, fruit $(p=0.03)$, and nut $(p=0.02)$.

\section{Discussion}

The current study was designed to compare the SQ of women with and without endometriosis and determine the relationship between lifestyle factors and SQ in women with endometriosis. Sleep as an essential factor on the physical and mental health can be change by many agents. The main finding of the current study showed that endometriosis has a negative impact on women's SQ. Our results also showed that scores of subjective sleep quality, sleep latency and sleep disturbance subscales were significantly less in patients than healthy women.

In consistence with our results, Leone et al.'s study showed that a high prevalence of poor SQ, daytime sleepiness, sub threshold insomnia, and moderate clinical insomnia was seen in women with endometriosis [12]. Another study demonstrated that night Shift job, especially working more than half of the shifts on a work at night, and Sleep Pattern Change on days off were associated with endometriosis risk [18]. The result of the one clinical trial demonstrates that in women with endometriosis, treatment with melatonin (10 mg for 8 weak) compared with placebo reduced daily pain, dysmenorrhea, dysuria, dyschezia, and need to use analgesic drugs, also improved SQ, and reduced the level of brainderived neurotropic factor (BDNF) [14].

Our finding reveal that in these patient, some lifestyle factors such as exercise, diet and clinical symptoms can modify this relationship. For example, a better SQ was seen in women with endometriosis who had a diet rich in dairy products, nut, and fruits. Dairy products and some fruit (banana, kiwi, apple, peach, strawberry, and orange) are sources of tryptophan. For melatonin production, tryptophan is converted to serotonin then to $\mathrm{N}$ acetyl serotonin, and finally to MLT [19]. Melatonin can regulate inflammation and immune function and protect against oxidative stress, therefore, in this way can reduce the risk of endometriosis [15]. Melatonin can also improve SQ in these women [14]. There is some evidence that shows sleep restriction can affect the composition of the intestinal microbiome. It seems that Mediterranean diets and other plant-rich diets with an effect on gut microbiome can improve the sleep quality of patients with cardiovascular disease [20].

It was seen that the consumption of kiwi, tart cherry juice, and oysters with the antioxidant, melatonin, and zinc contents can increase sleep duration and quality [21]. Healthy dietary patterns with low in saturated fat and high in vegetables, fruit, fiber, and seafood with potentially improving sleep quality can affect sleep [21].

Diet also considered as a main risk factor of endometriosis. Between dietary items, only consumption of the dairy product and fruit (including banana, kiwi, apple, peach, strawberry, and orange) were different between women with and without endometriosis. Some studies confirmed our results [22, 23].

Regarding the results, women with endometriosis were more likely to experience an increase in abnormal menstrual status, menorrhagia, dysmenorrhea, pelvic pain, abortion when compared with healthy women. Clinical symptoms of endometriosis such as 
Table 1 Demographic and lifestyle characteristics of Endometriosis cases and control women

\begin{tabular}{|c|c|c|c|c|}
\hline Characteristics & Case (78) & Control (77) & $P$-value & OR \\
\hline Age & $31.00 \pm 6.63$ & $29.35 \pm 6.99$ & 0.137 & 1.03(0.99-1.09) \\
\hline \multicolumn{5}{|l|}{ Age at menarche } \\
\hline Less than 11 year & $8(10.26)$ & $9(11.69)$ & \multirow[t]{2}{*}{0.77} & $0.86(0.31-2.37)$ \\
\hline More than 12 years & $70(89.74)$ & $68(87.18)$ & & $1.00^{\mathrm{a}}$ \\
\hline \multicolumn{5}{|l|}{ Education } \\
\hline Universitically & $42(53.85)$ & $38(49.35)$ & \multirow[t]{2}{*}{0.58} & $0.83(0.44-1.57)$ \\
\hline Non Universitically & $36(46.15)$ & $39(50.65)$ & & $1.00^{\mathrm{a}}$ \\
\hline BMI & $23.64 \pm 4.11$ & $23.69 \pm 3.58$ & 0.93 & $0.99(0.92-1.08)$ \\
\hline \multicolumn{5}{|l|}{ OCP use } \\
\hline Yes & 10(13.16) & $12(15.58)$ & \multirow[t]{2}{*}{0.67} & 0.82(0.33-1.03) \\
\hline No & $66(86.84)$ & $65(84.42)$ & & $1.00^{\mathrm{a}}$ \\
\hline \multicolumn{5}{|l|}{ Breast feeding history } \\
\hline Bottle feeding & $8(11.94)$ & $5(6.49)$ & \multirow[t]{2}{*}{0.37} & $1.69(0.53-2.43)$ \\
\hline Breast feeding & 68(89.47) & $72(93.51)$ & & $1.00^{\mathrm{a}}$ \\
\hline \multicolumn{5}{|l|}{ Family history } \\
\hline Yes & $11(14.10)$ & $3(3.90)$ & \multirow[t]{2}{*}{0.04} & $4.05(2.08-7.14)$ \\
\hline No & $67(85.90)$ & $74(96.19)$ & & $1.00^{\mathrm{a}}$ \\
\hline \multicolumn{5}{|l|}{ Abortion } \\
\hline Yes & $22(28.20)$ & $11(14.29)$ & \multirow[t]{2}{*}{0.04} & $2.36(1.05-3.28)$ \\
\hline No & $56(71.79)$ & $66(85.71)$ & & $1.00^{\mathrm{a}}$ \\
\hline \multicolumn{5}{|l|}{ Menstrual status } \\
\hline Regular & $55(71.43)$ & $67(87.01)$ & \multirow[t]{2}{*}{0.01} & $1.00^{\mathrm{a}}$ \\
\hline Irregular & $23(29.49)$ & 10(12.99) & & $2.80(1.23-4.38)$ \\
\hline \multicolumn{5}{|l|}{ Menorrhagia } \\
\hline Yes & $24(30.77)$ & 10(12.99) & \multirow[t]{2}{*}{0.007} & $2.98(1.31-3.76)$ \\
\hline No & $54(69.23)$ & $67(87.01)$ & & $1.00^{\mathrm{a}}$ \\
\hline \multicolumn{5}{|l|}{ Dysmenorrhea } \\
\hline Yes & $59(75.64)$ & $31(40.26)$ & \multirow[t]{2}{*}{$<0.001$} & $4.61(3.31-5.18)$ \\
\hline No & 19(24.36) & $46(59.74)$ & & $1.00^{\mathrm{a}}$ \\
\hline \multicolumn{5}{|l|}{ Pelvic pain } \\
\hline Yes & $44(56.41)$ & $6(7.79)$ & \multirow[t]{2}{*}{$<0.001$} & $15.31(12.95-17.43)$ \\
\hline No & $34(43.59)$ & $71(92.21)$ & & $1.00^{\mathrm{a}}$ \\
\hline \multicolumn{5}{|l|}{ Abortion } \\
\hline Yes & $22(28.20)$ & $11(14.29)$ & \multirow[t]{2}{*}{0.04} & $2.36(1.05-3.28)$ \\
\hline No & $56(71.79)$ & $66(85.71)$ & & $1.00^{\mathrm{a}}$ \\
\hline \multicolumn{5}{|l|}{ Physical activity } \\
\hline Less than $1 \mathrm{~h}$ per week & $41(52.56)$ & $26(33.77)$ & & $1.00^{\mathrm{a}}$ \\
\hline Between 2 and 3 per week & $22(28.20)$ & $19(24.67)$ & \multirow[t]{2}{*}{0.008} & $0.73(0.33-1.61)$ \\
\hline More than $3 \mathrm{~h}$ per week & 15(19.23) & $32(41.56)$ & & $0.30(0.13-0.65)$ \\
\hline \multicolumn{5}{|l|}{ Smoking } \\
\hline Yes & $6(7.69)$ & $3(3.90)$ & 0.31 & $2.06(0.49-3.53)$ \\
\hline No & 72(92.31) & $74(96.10)$ & & $1.00^{\mathrm{a}}$ \\
\hline
\end{tabular}

Data are demonstrated as $\mathrm{n}(\%)$ or mean $\pm \mathrm{SD}$

$O R$ Odds ratio, $C I$ Confidence interval, $B M I$ Body mass index, OCP Oral contraceptives

${ }^{\text {a }}$ Reference category 
Table 2 Comparison of sleep quality, and food intake between women with and without endometriosis

\begin{tabular}{|c|c|c|c|}
\hline & $\begin{array}{l}\text { Case }(N=78) \\
\text { mean } \pm S D\end{array}$ & $\begin{array}{l}\text { Control }(N=77) \\
\text { mean } \pm S D\end{array}$ & $P$-value \\
\hline Subjective sleep quality & $1.35 \pm 0.82$ & $0.97 \pm 0.74$ & 0.002 \\
\hline Sleep latency & $1.60 \pm 1.07$ & $0.96 \pm 0.95$ & $<0.001$ \\
\hline Duration of sleep & $0.36 \pm 0.68$ & $0.32 \pm 0.76$ & 0.324 \\
\hline Day time function & $0.97 \pm 1.01$ & $0.79 \pm 0.81$ & 0.383 \\
\hline Sleep disturbance & $1.38 \pm 0.63$ & $0.83 \pm 0.54$ & $<0.001$ \\
\hline Sleep efficiency & $0.47 \pm 0.77$ & $0.33 \pm 0.78$ & 0.07 \\
\hline Sleep medication & $0.33 \pm 0.81$ & $0.23 \pm 0.58$ & 0.844 \\
\hline Total score & $6.47 \pm 3.34$ & $4.45 \pm 3.26$ & $<0.001$ \\
\hline \multicolumn{4}{|l|}{ Fruit Item } \\
\hline Banana & $19.72 \pm 17.82$ & $24.65 \pm 21.19$ & 0.12 \\
\hline Peach & $21.55 \pm 19.30$ & $26.72 \pm 23.14$ & 0.218 \\
\hline Strawberry & $0.61 \pm 0.71$ & $0.83 \pm 1.69$ & 0.31 \\
\hline Kiwi & $15.84 \pm 17.59$ & $22.85 \pm 23.58$ & 0.10 \\
\hline Orange & $38.80 \pm 28.01$ & $51.26 \pm 39.58$ & 0.128 \\
\hline Apple & $39.56 \pm 34.13$ & $44.22 \pm 32.18$ & 0.28 \\
\hline Sum & $151.33 \pm 78.31$ & $188.93 \pm 94.96$ & 0.008 \\
\hline \multicolumn{4}{|l|}{ Dairy } \\
\hline Milk & $98.19 \pm 104$ & $135.45 \pm 17.63$ & 0.03 \\
\hline Cheese & $19.23 \pm 17.53$ & $17.14 \pm 13.54$ & 0.6 \\
\hline Yoghurt & $135.74 \pm 107.04$ & $187.13 \pm 150.78$ & 0.03 \\
\hline Total dairy product & $317.30 \pm 182.18$ & $401.91 \pm 217.65$ & 0.02 \\
\hline \multicolumn{4}{|l|}{ Nut } \\
\hline Peanut & $0.29 \pm 0.57$ & $0.28 \pm 0.49$ & 0.64 \\
\hline Pistachio & $0.63 \pm 0.99$ & $0.85 \pm 1.33$ & 0.45 \\
\hline Walnuts & $2.20 \pm 3.02$ & $2.35 \pm 2.46$ & 0.46 \\
\hline Almond & $0.72 \pm 1.24$ & $0.66 \pm 1.41$ & 0.23 \\
\hline Total nut & $3.85 \pm 4.59$ & $4.15 \pm 4.17$ & 0.61 \\
\hline \multicolumn{4}{|l|}{ Meat } \\
\hline Pultatory & $28.38 \pm 18.16$ & $26.81 \pm 18.75$ & 0.49 \\
\hline Fish & $9.35 \pm 8.33$ & $12.65 \pm 13.44$ & 0.15 \\
\hline Red meat & $20.76 \pm 17.58$ & $25.77 \pm 19.70$ & 0.07 \\
\hline Fast-food entrees & $12.37 \pm 16.09$ & $8.87 \pm 9.41$ & 0.26 \\
\hline Processed snacks & $12.17 \pm 17.57$ & $9.61 \pm 9.72$ & 0.37 \\
\hline
\end{tabular}

pain and menorrhagia can worse women's SQ. Loring et al. study demonstrated that increased deep sleep onset latency is associated with poor SQ, and besides, poor SQ leads to greater pain sensitivity the next day [10].

Our findings show that a lower level of physical activity in women with endometriosis. Regular physical exercise could be to improve levels of immune and antiinflammatory markers and reduced menstrual flow that could lead to decreased endometriosis risk [8].On the
Table 3 Quality of sleep among endometriosis women by socio-demographic, clinical characteristics and food intake

\begin{tabular}{|c|c|c|c|}
\hline Variable & $\begin{array}{l}\text { Good sleeper } \\
(\text { PSQI } \geq 5) \\
(N=31)\end{array}$ & $\begin{array}{l}\text { Poor sleeper } \\
\text { (PSQI < } 5) \\
(N=47)\end{array}$ & $P$-value \\
\hline Age & $31 \pm 7.02$ & $31.02 \pm 6.31$ & 0.99 \\
\hline \multicolumn{4}{|l|}{ Education } \\
\hline University & $17(54.84)$ & 19(40.42) & \multirow[t]{2}{*}{0.21} \\
\hline Non university & 14(45.16) & $28(59.57)$ & \\
\hline BMl & $23.13 \pm 3.20$ & $23.98 \pm 4.61$ & 0.37 \\
\hline \multicolumn{4}{|l|}{ Mense } \\
\hline Regular & 26(83.87) & 39(82.98) & \multirow[t]{2}{*}{0.92} \\
\hline Irregular & $5(16.13)$ & $8(17.02)$ & \\
\hline \multicolumn{4}{|l|}{ Menorrhagia } \\
\hline Yes & $9(29.03)$ & 15(31.91) & \multirow[t]{2}{*}{0.79} \\
\hline No & 2270.97) & $32(68.08)$ & \\
\hline \multicolumn{4}{|l|}{ Dysmenorrhea } \\
\hline Yes & $20(64.52)$ & $40(85.11)$ & \multirow[t]{2}{*}{0.03} \\
\hline No & $11(35.48)$ & $7(14.89)$ & \\
\hline \multicolumn{4}{|l|}{ Dyspareunia } \\
\hline Yes & $11(35.48)$ & $28(59.57)$ & \multirow[t]{2}{*}{0.04} \\
\hline No & $20(64.52)$ & 19(40.43) & \\
\hline \multicolumn{4}{|l|}{ Pelvic pain } \\
\hline Yes & 12(38.71) & $31(65.96)$ & \multirow[t]{2}{*}{0.02} \\
\hline No & 19(61.29) & 16(34.04) & \\
\hline \multicolumn{4}{|l|}{ Physical activity } \\
\hline Less than $1 \mathrm{~h}$ & $9(29.03)$ & $33(70.21)$ & \\
\hline Between 2 and $3 \mathrm{~h}$ & 10(32.26) & $11(23.40)$ & \multirow[t]{2}{*}{$<0.001$} \\
\hline More than $3 \mathrm{~h}$ & $12(38.71)$ & $3(6.38)$ & \\
\hline \multicolumn{4}{|l|}{ Diet } \\
\hline Dairy product & $375.56 \pm 157.67$ & $278.88 \pm 188.53$ & 0.02 \\
\hline Red Meat & $18.90 \pm 16.32$ & $21.98 \pm 18.75$ & 0.47 \\
\hline Fish & $8.37 \pm 8.39$ & $9.99 \pm 8.32$ & 0.32 \\
\hline Pultatory & $28.27 \pm 17.38$ & $28.45 \pm 18.84$ & 0.92 \\
\hline Nut & $6.14 \pm 7.49$ & $2.93 \pm 2.99$ & 0.01 \\
\hline Fruit & $227.23 \pm 68.94$ & $244 \pm 75.70$ & 0.03 \\
\hline
\end{tabular}

other hand, in women with a higher level of exercise, increased levels of sex hormone-binding globulin (SHBG) can lead to reducing the level of bioavailable estrogen [8]. Insulin resistance and hyperinsulinemia have been related to endometriosis risk that physical activity can reduce these. In the result of one meta-analysis that integrated the results of nine studies, physical activity may reduce endometriosis risk, although this relationship was not statistically significant [8].

We also found that exercise is a main modifier that can improve SQ of women with endometriosis. Regular exercise can enhance melatonin secretion and in this 
way improve the SQ of patients with insomnia [24]. On the other hand in these women issues such as pain or abnormal cycle may decrease their tendency for exercise.

Recently, several studies were conducted on the influence of endometriosis on SQ. To our knowledge, this survey is the first research which assessed the role of life style factors on SQ of women with endometriosis. The use of validated questionnaires (eg, FFQ, and PSQI), and confirmed diagnosis through laparoscopy are other strengths of this study.

Despite the strengths of the study, some limitations should be noted. First, we don't use a validated questionnaire for evaluating physical activity. Second, like other case-control studies, selection and recall bias are a concern for this study.

\section{Conclusion}

Lifestyle factor such as diet and physical activity have a major impact on endometriosis risk. In women with endometriosis, SQ was lower than healthy individuals. Fruit, dairy, and nut consumption, and exercise can effect on SQ of endometriosis women. Therefore, counseling about diet and physical exercise in these women is recommended.

\section{Abbreviations}

FFQ: Food Frequency Questionnaire; PSQI: Pittsburgh Sleep Quality Index; SQ: Sleep quality; SHBG: Sex hormone-binding globulin; MLT: Melatonin

\section{Acknowledgements}

This study was carried out with the kind collaboration of the participants. We would also like to appreciate of the staff of Arash Hospital for their valuable contributions. This study is a part of research work done in Tarbiat Modares University, Tehran, Iran. There were no conflicts of interest.

\section{Authors' contributions}

S.J.S, A.K, A.M1 [Azadeh Mottaghi], A.M2, S.Y contributed to the conception and design of the study; SY, and G.R did the literature search; S.Y and G.R contributed to data collection; A.K performed the statistical analysis; SY, A.M1, G.R, A.M2 and S.J.S wrote the first draft of the manuscript. All authors contributed to manuscript revision, read, and approved the submitted version.

\section{Funding}

There are no sources of funding for this research.

\section{Availability of data and materials}

The data sets used and analyzed during the current study are available from the corresponding author on reasonable request.

\section{Ethics approval and consent to participate}

The study was approved by the Tarbiat Modares University of Medical Sciences (IR.TMU.REC.1396.659). All procedures were in accordance with the ethical standards of the Regional research committee and with the Declaration of Helsinki 1964 and it later amendments. Written informed consent was obtained from all participants included in the current study.

\section{Consent for publication}

Not Applicable.

\section{Competing interests}

The authors declare no conflict of interest.

\section{Author details}

${ }^{1}$ Department of Midwifery and Reproductive Health, Faculty of Medical Sciences, Tarbiat Modares University, Tehran, Iran. ${ }^{2}$ Research Center for Prevention of Cardiovascular Diseases, Institute of Endocrinology \& Metabolism, Iran University of Medical Sciences, Tehran, Iran. ${ }^{3}$ Department of Biostatistics, Faculty of Medical Sciences, Tarbiat Modares University, Tehran, Iran. ${ }^{4}$ Department of Obstetrics and Gynecology, School of Medicine, Tehran University of Medical Science, Tehran, Iran. ${ }^{5}$ Department of Obstetrics and Gynecology, Arash Women's Hospital, Tehran University of Medical Sciences, Tehran, Iran. ${ }^{6}$ Department of Endocrinology and Female Infertility, Reproductive Biomedicine Research Center, Royan Institute for Reproductive Biomedicine, ACECR, Tehran, Iran.

Received: 29 February 2020 Accepted: 27 July 2020

Published online: 10 August 2020

\section{References}

1. Johnson NP, Hummelshoj L, Adamson GD, Keckstein J, Taylor HS, Abrao MS, et al. World endometriosis society consensus on the classification of endometriosis. Hum Reprod. 2017;32(2):315-24.

2. Ghiasi M, Kulkarni MT, Missmer SA. Is endometriosis more common and more severe than it was 30 years ago? J Minim Invasive Gynecol. 2020;27(2): 452-61.

3. Moini A, Malekzadeh F, Amirchaghmaghi E, Kashfi F, Akhoond MR, Saei M, et al. Risk factors associated with endometriosis among infertile Iranian women. Arch Med Sci. 2013;9(3):506.

4. Patel BG, Lenk EE, Lebovic DI, Shu Y, Yu J, Taylor RN. Pathogenesis of endometriosis: interaction between endocrine and inflammatory pathways. Best Pract Res Clin Obstet Gynaecol. 2018;50:50-60.

5. Wang Y, Nicholes K, Shih I-M. The origin and pathogenesis of endometriosis. Annu Rev Pathol. 2019;15:71-95.

6. Parazzini F, Esposito G, Tozzi L, Noli S, Bianchi S. Epidemiology of endometriosis and its comorbidities. Eur J Obstet Gynecol Reprod Biol. 2017;209:3-7.

7. Saha R, Kuja-Halkola R, Tornvall P, Marions L. Reproductive and lifestyle factors associated with endometriosis in a large cross-sectional population sample. J Women's Health. 2017;26(2):152-8.

8. Ricci E, Viganò P, Cipriani S, Chiaffarino F, Bianchi S, Rebonato G, et al. Physical activity and endometriosis risk in women with infertility or pain: systematic review and meta-analysis. Medicine. 2016;95(40):e4957.

9. Parazzini $F$, Viganò $\mathrm{P}$, Candiani $M$, Fedele L. Diet and endometriosis risk: a literature review. Reprod BioMed Online. 2013;26(4):323-36.

10. Loring M, Kabelac Z, Munir U, Yue S, Ephraim HY, Morris SN, et al. Assessing pain and sleep patterns in endometriosis: a pilot study using passive radio sensors. J Minim Invasive Gynecol. 2019;26(7, Supplement):S89.

11. Davari-Tanha F, Askari F, Akrami M, Mohseni M, Ghajarzadeh M. Sleep quality in women with endometriosis. Acad J Surg. 2014;1(3-4):57-9.

12. Leone Roberti Maggiore U, Bizzarri N, Scala C, Tafi E, Siesto G, Alessandri F, et al. Symptomatic endometriosis of the posterior cul-de-sac is associated with impaired sleep quality, excessive daytime sleepiness and insomnia: a case-control study. Eur J Obstet Gynecol Reprod Biol. 2017;209:39-43.

13. Arion K, Orr NL, Noga H, Allaire C, Williams C, Bedaiwy MA, et al. Journal of Women's Health.ahead of print https://doi.org/10.1089/jwh.2019.8008.

14. Schwertner A, Conceição dos Santos CC, Costa GD, Deitos A, de Souza A, de Souza ICC, et al. Efficacy of melatonin in the treatment of endometriosis: a phase II, randomized, double-blind, placebo-controlled trial. Pain. 2013; 154(6):874-81.

15. Yang HL, Zhou WJ, Gu CJ, et al. Pleiotropic roles of melatonin in endometriosis, recurrent spontaneous abortion, and polycystic ovary syndrome. Am J Reprod Immunol. 2018;80(1):e12839. https://doi.org/10. 1111/aji.12839.

16. Mirmiran P, Esfahani FH, Mehrabi Y, Hedayati M, Azizi F. Reliability and relative validity of an FFQ for nutrients in the Tehran lipid and glucose study. Public Health Nutr. 2010;13(5):654-62.

17. Moghaddam JF, Nakhaee N, Sheibani V, Garrusi B, Amirkafi A. Reliability and validity of the Persian version of the Pittsburgh Sleep Quality Index (PSQI-P). Sleep Breath. 2012:16(1):79-82.

18. Marino JL, Holt VL, Chen C, Davis S. Shift work, hCLOCK T3111C polymorphism, and endometriosis risk. Epidemiology (Cambridge, Mass). 2008;19(3):477-84 
19. Yu H-S, Reiter RJ. Melatonin: biosynthesis, physiological effects, and clinical applications: CRC Press; 1992.

20. St-Onge M-P, Zuraikat FM. Reciprocal roles of sleep and diet in cardiovascular health: a review of recent evidence and a potential mechanism. Curr Atheroscler Rep. 2019;21(3):11.

21. Zuraikat FM, St-Onge M-P. Chapter 22 - the influence of diet on sleep. In: Watson RR, Preedy VR, editors. Neurological modulation of sleep: Academic; 2020. p. 205-15.

22. Trabert B, Peters U, De Roos AJ, Scholes D, Holt VL. Diet and risk of endometriosis in a population-based case-control study. Br J Nutr. 2011; 105(3):459-67.

23. Harris HR, Chavarro JE, Malspeis S, Willett WC, Missmer SA. Dairy-food, calcium, magnesium, and vitamin D intake and endometriosis: a prospective cohort study. Am J Epidemiol. 2013;177(5):420-30.

24. Taheri $\mathrm{M}$, Irandoust $\mathrm{K}$. The exercise-induced weight loss improves selfreported quality of sleep in obese elderly women with sleep disorders Sleep Hypn. 2018;20(1):54-9.

\section{Publisher's Note}

Springer Nature remains neutral with regard to jurisdictional claims in published maps and institutional affiliations.

Ready to submit your research? Choose BMC and benefit from:

- fast, convenient online submission

- thorough peer review by experienced researchers in your field

- rapid publication on acceptance

- support for research data, including large and complex data types

- gold Open Access which fosters wider collaboration and increased citations

- maximum visibility for your research: over $100 \mathrm{M}$ website views per year

At BMC, research is always in progress.

Learn more biomedcentral.com/submissions 